\title{
Predição da Composição Corporal por Intermédio de Método Indireto
}

\section{Marcelo de Andrade Ferreira ${ }^{1}$, Sebastião de Campos Valadares Filho ${ }^{2}$, Antonia Sherlânea Chaves Veras ${ }^{1}$, Gherman Garcia Leal Araújo ${ }^{3}$, Ricardo Dias Signoretti ${ }^{4}$}

\begin{abstract}
RESUMO - O objetivo deste trabalho foi desenvolver equações de predição da composição química corporal de bovinos mestiços $\mathrm{F}_{1}$ Simental x Nelore, por intermédio da análise química da amostra representativa da carcaça. Utilizaram-se 29 animais, não- castrados, com idade média de 17 meses e peso vivo inicial de $354 \mathrm{~kg}$. Cinco animais foram abatidos ao início do experimento e os demais, distribuídos, inteiramente ao acaso, nos tratamentos que foram definidos de acordo com o nível de concentrado na ração (25; 37,5; 50; 62,5; e 75\%). Os conteúdos corporais de proteína, gordura, energia e minerais foram determinados analisando-se amostras de seção da carcaça incluindo a 9ạ , 10 a e 11 1 a costelas, de acordo com HANKINS E HOWE (1946) (seção HH), e dos demais tecidos corporais Os teores de proteína, gordura, energia e minerais, com exceção do magnésio, da seção HH, mostraram-se altamente correlacionados com a composição química do corpo vazio.
\end{abstract}

Palavras-chave: bovinos, composição corporal, equações de predição

\section{Use of Indirect Method to Predict Chemical Body Composition}

ABSTRACT - The objective of the research was to develop equations to predict the chemical body composition of $F_{1}$ Simmental $\mathrm{x}$ Nellore, based on the chemical composition of rib joints. Twenty-nine F1 Simmental x Nellore bulls, averaging 17 months of age and initial live weight of $354 \mathrm{~kg}$, were used. Five animals were slaughtered at the beginning of the experiment and the others were randomly allotted to the treatments designed according to the concentrate levels in the diet $(25,37.5,50,62.5$, and $75 \%)$. Body contents of protein, fat, energy and ash were determined from the analysis of carcass joint, including the $9^{\text {th }}, 10^{\text {th }}$ and $11^{\text {th }}$ ribs, according to HANKINS E HOWE (1946) (HH joint), and the remaining body tissues. The contents of protein, fat, energy and ash, except magnesium, from the HH joint, were closely correlated to the chemical empty body composition.

Key Words: body composition, cattle, prediction equations

\section{Introdução}

As proporções de gordura, músculos e ossos, em determinado estádio de desenvolvimento de animais de corte, são de interesse do produtor e, especialmente, do consumidor. O teor de gordura da carcaça afeta a aceitabilidade por parte do consumidor, e sabe-se que o período de terminação é o mais dispendioso. Dessa forma, é importante que métodos rápidos e econômicos, para estimar a composição física e química da carcaça e de seus cortes, estejam disponíveis para produtores e pesquisadores (HANKINS e HOWE, 1946).

HANKINS e HOWE (1946), em um trabalho clássico sobre a utilização de cortes da carcaça para predição da composição física e química da carcaça de bovinos, definiram uma metodologia para obtenção de uma amostra da carcaça compreendendo a 9 ${ }^{a}, 10^{\underline{a}}$ e 11 a costelas (Seção HH), bem como equações de predição, que, atualmente, são amplamente utilizadas por pesquisadores norte-americanos e brasileiros. Estas equações tiveram sua validade confirmada por COLE et al. (1962), POWELL e HUFFMAN (1968) e LANNA (1988).

Com relação à composição química da carcaça de bovinos, HANKINS e HOWE (1946) observaram correlações significativas de 0,$83 ; 0,91$; e 0,53 entre os teores de proteína, gordura e cinzas da seção HH e aqueles obtidos por análise química da carcaça. Recentemente, NOUR e THONNEY (1994), em um trabalho com bovinos das raças Angus e Holandês, concluíram que a composição da seção HH pode ser utilizada com precisão na predição da composição da carcaça, salvo pequenos ajustes em relação à raça.

Outro método que tem sido utilizado para estimar a composição corporal de bovinos é o da gravidade específica da carcaça ou de partes da mesma.

\footnotetext{
${ }^{1}$ Professor Adjunto do Depto. de Zootecnia da UFRPE. E.mail: mcelo@yahoo.com; sherlanea@uol.com.br

2 Professor Titular do Depto. de Zootecnia da UFV. E.mail: scvfilho@mail.ufv.br

3 Pesquisador da EMBRAPA/CPATSA. E.mail: ggla@cpatsa.embrapa.br

4 Engenheiro-Agrônomo, Doutor em Zootecnia. E.mail: rsignoretti@axtnet.com.br
} 
SALVADOR (1980) e TEIXEIRA (1984), comparando a composição da carcaça estimada por análise química da seção HH e por gravidade específica da carcaça, não observaram diferenças significativas entre os dois métodos. Contrariamente, LANNA (1988) observou baixas correlações entre a gravidade específica da carcaça e os teores de água, gordura e proteína na seção $\mathrm{HH}(0,49 ;-0,61$; e 0,65 , respectivamente).

PERON et al. (1993) obtiveram resultados nãosatisfatórios, para animais magros, utilizando-se a gravidade específica da carcaça. Da mesma forma, GIL et al. (1970) observaram que a precisão do método é questionável, quando bovinos apresentam menos de $20 \%$ de gordura na carcaça. Já PRESTON et al. (1974), em revisão de literatura, relataram que o teor mínimo de gordura no corpo vazio estaria entre 12 e $15 \%$.

Mesmo admitindo-se que o método mais acurado para determinação da composição corporal de bovinos é a análise química do corpo inteiro após a eliminação do conteúdo do trato digestivo e bexiga (HANKINS e HOWE, 1946), o objetivo deste trabalho foi obter equações de predição da composição corporal, a partir da composição química de secção da carcaça, em função da praticidade e economia proporcionadas pelo método.

\section{Material e Métodos}

O experimento foi conduzido nas dependências do Departamento de Zootecnia da Universidade Federal de Viçosa, no período de fevereiro a outubro de 1996.

Foram utilizados 29 bovinos, não-castrados, $\mathrm{F}_{1}$ Nelore x Simental, com idade média de 17 meses e peso vivo médio inicial de $354 \mathrm{~kg}$. Após um período de adaptação de 45 dias, em que os animais receberam o mesmo tratamento, cinco animais foram abatidos, servindo como referência no estudo da composição corporal inicial dos animais; o restante (24 animais) foi distribuído inteiramente ao acaso nos tratamentos, de acordo com o nível de concentrado na ração (25; $37,5 ; 50 ; 62 ; 5 ;$ e $75 \%)$. No tratamento com $62,5 \%$ de concentrado na ração, foram usados quatro animais. Os animais foram alimentados à vontade, sendo a ração distribuída uma vez por dia, pela manhã, ajustando-se sobra diária de aproximadamente $10 \%$ do oferecido. A quantidade de alimentos fornecida foi registrada diariamente, enquanto as sobras, semanalmente. Como volumoso, foram utilizados os fenos de coast-cross (Cynodon dactilum) e braquiária (Brachiaria decumbens). As rações experimentais (feno + concentrado) foram formuladas de acordo com o Cornell Net Carbohydrate and Protein System -CNCPS (BARRY et al., 1994) e sua composição encontra-se na Tabela 1.

Os animais foram pesados ao início do experimento e a cada 28 dias, adotando-se pesagens intermediárias, para que fosse obtido peso de abate preestabelecido de $500 \mathrm{~kg}$. Antes da pesagem, os animais passaram por jejum prévio de 16 horas. De cada animal abatido, pesaram-se e coletaram-se amostras de cabeça, couro, pés, rúmen, retículo, omaso, abomaso, intestino grosso, intestino delgado, mesentério, gordura interna (pélvica e renal), coração, rins, fígado, baço, pulmão, língua, sangue, esôfago, traquéia e aparelho reprodutor. As duas meia-carcaças foram pesadas no dia do abate e, posteriormente, levadas à câmara fria a $-5^{\circ} \mathrm{C}$, durante um período de 18 horas. Após esse período, foram retiradas da

Tabela 1 - Teores de matéria seca (MS), proteína bruta (PB), extrato etéreo (EE), fibra em detergente neutro e nutrientes digestíveis totais (NDT) das rações experimentais

Table 1 - Contents of dry matter (DM), crude protein (CP), ether extract (EE), neutral detergent fiber(NDF) and total digestible nutrients $(T D N)$ of the experimental diets

\begin{tabular}{|c|c|c|c|c|c|}
\hline \multirow[t]{2}{*}{ Item } & \multicolumn{5}{|c|}{$\begin{array}{l}\text { Nível de concentrado (\%) } \\
\text { Level of concentrate }\end{array}$} \\
\hline & 25 & 37,5 & 50 & 62,5 & 75 \\
\hline $\mathrm{MS}(D M)(\%)$ & 88,25 & 88,22 & 87,83 & 87,71 & 88,11 \\
\hline $\mathrm{PB}(C P)^{1}$ & 8,48 & 10,82 & 13,01 & 15,28 & 16,90 \\
\hline $\mathrm{EE}^{1}$ & 1,98 & 2,14 & 2,42 & 2,75 & 3,06 \\
\hline $\mathrm{FDN}(N D F)^{l}$ & 63,12 & 53,71 & 46,34 & 36,20 & 27,69 \\
\hline $\operatorname{NDT}(T D N)^{1}$ & 63,08 & 62,51 & 67,31 & 71,33 & 75,26 \\
\hline
\end{tabular}

$1 \%$ na MS (\% in DM). 
244 Rev. bras. zootec.

câmara fria, coletando-se uma amostra representativa da meia-carcaça esquerda, correspondendo à secção compreendida entre a $9^{\mathrm{a}}$ e $11^{\mathrm{a}}$ costelas (seção HH), de acordo com HANKINS e HOWE (1946), para posteriores pesagens, dissecações, avaliações dos componentes físicos das carcaças e análises laboratoriais. Na seção $\mathrm{HH}$, foram determinadas as proporções de músculo, tecido adiposo e ossos, estimando-se as proporções correspondentes na carcaça, por meio das seguintes equações preconizadas por HANKINS e HOWE (1946):

Músculo: $\mathrm{Y}=16,08+0,80 \mathrm{X}$;

Gordura: $\mathrm{Y}=3,54+0,80 \mathrm{X}$; $\mathrm{e}$

Ossos: $\quad \mathrm{Y}=5,52+0,57 \mathrm{X}$

em que $\mathrm{X}$ é a porcentagem do componente na seção HH.

As amostras de rúmen, retículo, omaso, abomaso, intestino delgado, intestino grosso, gordura interna e mesentério foram agrupadas de forma proporcional, constituindo-se em amostras de vísceras. Semelhantemente, as amostras de fígado, coração, rins, pulmão, língua, baço, carne industrial (diafragma), esôfago, traquéia e aparelho reprodutor foram agrupadas proporcionalmente, constituindo-se amostras compostas de órgãos.

As amostras de sangue (400 g) foram coletadas, imediatamente após o abate, acondicionadas em pirex e levadas à estufa de ventilação forçada, a $55-60^{\circ} \mathrm{C}$, durante 48 horas, para determinação da matéria seca, sendo, a seguir, moídas em moinho de bola. As amostras de carne $(150 \mathrm{~g})$, gordura (200 g), vísceras (200 g) e órgãos (200 g), depois de moídas, e as de couro, ossos e cauda (100 g), após seccionadas, foram colocadas em vidros de $500 \mathrm{~mL}$ e levadas à estufa, a $105^{\circ} \mathrm{C}$, durante um período de 48 a 72 horas, dependendo do teor de gordura, para determinação da matéria seca gordurosa (MSG). Em seguida, foram submetidas a um processo de extração de gordura com éter de petróleo, obtendo-se a matéria seca pré-desengordurada (MSPD). As amostras prédesengorduradas foram, posteriormente, moídas em moinho de bola, antes de se proceder às análises de laboratório.

As determinações de nitrogênio total, extrato etéreo, cinzas, minerais e FDN foram feitas segundo SILVA (1990).

Os conteúdos corporais de gordura, proteína e minerais foram determinados em função das concentrações percentuais destes nas vísceras, nos órgãos, couro, sangue, cauda, cabeça, pés (gordura e osso) e componentes separados - músculos, gordura e osso da seção HH. O peso de corpo vazio aproximado dos animais foi determinado pela soma dos pesos de carcaça, sangue, cabeça, couro, cauda, pés, vísceras e órgãos.

O conteúdo corporal de energia foi determinado a partir dos conteúdos corporais de proteína e gordura e dos respectivos equivalentes calóricos, conforme a equação abaixo (AGRICULTURAL RESEARCH COUNCIL - ARC, 1980):

$$
\mathrm{CE}(\mathrm{Mcal})=5,6405 \mathrm{X}+9,3929 \mathrm{Y}
$$

em que $\mathrm{CE}$ é conteúdo de energia; $\mathrm{X}$, proteína corporal $(\mathrm{kg})$; e Y, gordura corporal $(\mathrm{kg})$.

Equações de regressão para predição da composição química corporal (proteína, gordura, energia e minerais) foram ajustadas em função da composição química da secção HH.

\section{Resultados e Discussão}

Os parâmetros das equações de predição das porcentagens de proteína e gordura e do conteúdo de energia no corpo vazio, em função das porcentagens de proteína e gordura e do conteúdo de energia na seção HH, são apresentados na Tabela 2. Pode-se verificar que os teores de proteína, gordura e energia na seção $H H$ mostraram-se altamente correlacionados $(\mathrm{P}<0,01)$ com os teores dos mesmos componentes no corpo vazio, como pode ser observado pelos altos valores dos coeficientes de correlação e pelos baixos valores dos coeficientes de variação. De maneira semelhante, PERON et al. (1993) verificaram correlações significativas de 0,93 e 0,99 para proteína e gordura, respectivamente. JORGE et al. (1998), utilizando a mesma metodologia, obtiveram equações de predição de proteína, gordura e energia com $\mathrm{r}^{2}=0,84 ; 0,88$; e 0,88 , respectivamente. HENRIQUE et al. (1999) e ALLEONI et al. (1999) também concluíram que a porcentagem de extrato etéreo na seção $\mathrm{HH}$ se mostrou altamente correlacionada com a composição química do corpo vazio, porém o mesmo não ocorreu para o teor de proteína.

Os parâmetros das equações de predição das porcentagens de cálcio, fósforo, magnésio, potássio e sódio no corpo vazio, em função das porcentagens dos mesmos na seção HH, são apresentados na Tabela 3. Com exceção do magnésio, a concentração de todos os outros elementos minerais na seção $\mathrm{HH}$ mostrou-se altamente correlacionados $(\mathrm{P}<0,01)$ com a concentração dos mesmos no corpo vazio, 
FERREIRA et al.

Tabela 2 - Parâmetros das equações de regressão (PER) das porcentagens de proteína e gordura e do conteúdo corporal de energia (Mcal/kg de corpo vazio) no corpo vazio, em função das porcentagens de proteína e gordura e do conteúdo de energia na seção $\mathrm{HH}$ (mcal/kg de seção $\mathrm{HH}$ ), determinadas por análises químicas

Table 2 - Parameters of the regression equations (PRE) for the percentage of protein and fat and body content of energy (Mcal/kg of empty body) in the empty body on the percentage of protein and fat and the energy content in the $\mathrm{HH}$ section (Mcal/ $\mathrm{kg}$ of $\mathrm{HH}$ joint), determined by chemical analyses

\begin{tabular}{lcccc}
\hline Item & \multicolumn{2}{c}{ PER } & $\mathrm{r}$ & $\mathrm{CV}(\%)$ \\
\cline { 2 - 4 } & $\begin{array}{c}\text { Intercepto } \\
\text { Intercept }\end{array}$ & $\begin{array}{c}\text { Coeficiente de regressão } \\
\text { Coefficient of regression }\end{array}$ & $0,97^{* *}$ & 1,22 \\
\hline $\begin{array}{l}\text { Proteína } \\
\text { Protein }\end{array}$ & 4,4943 & 0,7624 & $0,98^{* *}$ & 4,95 \\
$\begin{array}{l}\text { Gordura } \\
\text { Fat }\end{array}$ & 0,7278 & 0,9153 & $0,96^{* *}$ & 2,70 \\
$\begin{array}{l}\text { Energia } \\
\text { Energy }\end{array}$ & 0,1354 & 0,9315 & & \\
\hline
\end{tabular}

** Significativo pelo teste $\mathrm{t}(\mathrm{P}<0,01)$.

** Significant by $t$ test $(P<.01)$.

Tabela 3 - Parâmetros das equações de regressão (PER) das porcentagens de cálcio (Ca), fósforo $(P)$, potássio $(\mathrm{K})$, magnésio $(\mathrm{Mg})$ e sódio $(\mathrm{Na})$ no corpo vazio, em função das porcentagens de cálcio, fósforo, potássio, magnésio e sódio na seção $\mathrm{HH}$, determinadas por análises químicas

Table 3 - Parameters of the regression equations (PRE) for percentage of calcium (Ca), phosphorus (P), potassium (K) and sodium ( $\mathrm{Na}$ ) in the empty body on the percentage of calcium, phosphorus, potassium and sodium in the HH section, determined by chemical analyses

\begin{tabular}{lcccc}
\hline Item & \multicolumn{2}{c}{ PER } & $\mathrm{r}$ & $\mathrm{CV}(\%)$ \\
\cline { 2 - 4 } & $\begin{array}{c}\text { Intercepto } \\
\text { Intercept }\end{array}$ & $\begin{array}{c}\text { Coeficiente de regressão } \\
\text { Coefficient of regression }\end{array}$ & $0,96^{* *}$ & 2,90 \\
$\mathrm{Ca}$ & 0,4619 & 0,4697 & $0,97^{* *}$ & 2,91 \\
$\mathrm{P}$ & 0,2673 & 0,5107 & $0,55^{* *}$ & 5,30 \\
$\mathrm{Mg}$ & 0,0083 & 0,7939 & $0,98^{* *}$ & 1,10 \\
$\mathrm{~K}$ & 0,0285 & 0,6974 & $0,98^{* *}$ & 2,70 \\
$\mathrm{Na}$ & 0,1354 & 0,9315 & & \\
\hline
\end{tabular}

** Significativo pelo teste $\mathrm{t}(\mathrm{P}<0,01)$.

** Significant by $t$ test $(P<.01)$.

como pode ser verificado pelos valores dos coeficientes de correlação e variação. Da mesma forma, JORGE et al.(1998) também verificaram, com exceção do magnésio, estreita relação entre os teores de cálcio, fósforo, potássio e sódio na seção $\mathrm{HH}$ e aqueles verificados no corpo vazio. Por outro lado, ALHASSAN et al. (1975), HENRIQUE et al. (1999) e ALLEONI et al. (1999) não obtiveram equações para estimar, com precisão, o conteúdo de minerais no corpo vazio a partir da concentração dos mesmos na seção $\mathrm{HH}$.
Vale ressaltar que a seção HH serviu de base para a determinação da composição do corpo vazio, o que pode explicar, em parte, os altos valores de correlação obtidos no presente trabalho.

\section{Conclusões}

Os teores de proteína, gordura, energia e macroelementos minerais, com exceção do magnésio, na seção HH, mostraram-se altamente correlacionados com aqueles verificados no corpo vazio. 


\section{Referências Bibliográficas}

AGRICULTURAL RESEARCH COUNCIL - ARC. 1980. The nutrients requirements of ruminant livestock. London: Commonwealth Agricultural Bureaux. 351p.

ALHASSAN, W.S., BUCHANAN-SMITH, J.G., USBORNE, W.R. et al. 1975. Predicting empty body composition of cattle from carcass weight and rib cut composition. Can. J. Anim. Sci., 55(3):369-376.

ALLEONI, G.F., LEME, P.R., BOIN, C. et al. Equações de estimativa da composição química corporal de novilhos Nelore a partir da composição física e química dos cortes da costela. In: REUNIÃO ANUAL DA SOCIEDADE BRASILEIRA DE ZOOTECNIA, 36, 1999, Porto Alegre. Anais...Porto Alegre: SBZ, 1998. CD-ROM.

BARRY, M.C., FOX, D.C., TYLUTKY, T.P. et al. 1994. A manual for using the cornell net carbohydrate and protein system for evaluating cattle diets. Revised for CNCPS. 3.ed Ithaca. 40p.

COLE, J.W., RAMSEY, C.B., EPLEY, R.H. 1962. Simplified method for predicting pounds of lean in beef carcass. J. Anim. Sci., 21(2):355-361.

JORGE, A.M., FONTES, C.A.A., PAULINO, M.F. et al. Predição da composição química corporal de zebuínos através de método indireto. In: REUNIÃO ANUAL DA SOCIEDADE BRASILEIRA DEZOOTECNIA, 35, 1998, Botucatu. Anais... Botucatu: SBZ, 1998. p. 233-235.

HANKINS, O.G., HOWE, P.E. 1946. Estimation of the composition of beef carcass and cuts. Washington, D.C. (Technical Bulletin - USDA, 926).

HENRIQUE, W., LEME, P.R., LANNA, D.P.D. et al. Equações para estimativa da composição química corporal de tourinhos santa gertrudis a partir do corte das 9-10-11 $\underline{\text { a }}$ costelas. In: REUNIÃO ANUAL DA SOCIEDADE BRASILEIRA DE ZOOTECNIA, 36, 1999, Porto Alegre. Anais...Porto Alegre: SBZ, 1998. CD-ROM.

LANNA, D.P.D. Estimativa da composição química do corpo vazio de tourinhos nelore através da gravidade específica da carcaça e da composição de cortes das costelas. Piracicaba, SP: ESALQ, 1988. 131p. Dissertação (Mestrado em Zootecnia) Escola Superior de Agricultura Luiz de Queiroz, 1988.
NOUR, A.Y.M, THONNEY, M.L.1994 Chemical composition of angus and holstein carcasses predicted from rib section composition. J. Anim. Sci., 72(5):1239-1241.

PERON, A.J., FONTES, C.A.A., LANA, R.P. et al. 1993. Predição da composição corporal e da carcaça de bovinos através de métodos indiretos. R. Soc. Bras. Zootec., 22(2):227-237.

POWELL, W.E., HUFFMAN, D.L. 1968. An evaluation of quantitative estimates of beef carcass composition. J. Anim. Sci., 27(6):1554-1558.

PRESTON, R.L., VANCE, R.D., CAHILL, V.R. et al. 1974. Carcass specific gravity and carcass composition in cattle and the effect of bone proportionality on this relationship. J. Anim. Sci., 38(1):47-51.

SALVADOR, M. Exigências de energia e proteína para engorda de novilhos azebuados. Viçosa, MG: UFV, 1980. 70p. Tese (Doutorado em Zootecnia) - Universidade Federal de Viçosa, 1980.

SILVA, D.J. 1990. Análise de alimentos (métodos químicos e biológicos).Viçosa: UFV. 166p.

TEIXEIRA, J.C. Exigências de energia e proteína, composição e área corporal e principais cortes da carcaça em seis grupos genéticos de bovídeos. Viçosa: UFV. 94p. 1984. Dissertação (Mestrado em Zootecnia) - Universidade Federal de Viçosa, 1984.

Recebido em: 10/11/99

Aceito em: 19/10/00 